Ärztliche Erfahrung beschränkt sich nicht auf medizinisches Fachwissen.

\title{
Heilpraktiker lässt Schulterschmerz schleifen
}

_ Immer wieder wundert es mich, wie geduldig sich auch intelligente Patienten Stümpereien von Heilpraktikern bieten lassen - und diese auch noch teuer bezahlen. Neulich z. B. kam ein Mann mit Schulterschmerzen zu mir in die Praxis. „Es tut nun schon seit einem Jahr weh“, klagte er. Ich untersuchte ihn und stellte ein deutliches Impingement fest. Viele Bewegungen waren gar nicht oder nur unter starken Schmerzen möglich.

„Das haben Sie aber lange ertragen“, sagte ich verwundert. „Haben Sie denn bisher gar nichts unternommen?" Seine Antwort frustrierte mich: „Doch, ich war die ganze Zeit beim Heilpraktiker in Behandlung. Das hat aber nichts gebracht“. „Warum gehen Sie überhaupt zu einem Heilpraktiker?", fragte ich neugierig. „Der hat doch im Verhältnis zum Arzt nur eine Schmalspurausbildung!“ Die Antwort kam prompt: „Ein Kollege von mir hatte ein ähnliches Problem und hat vom Arzt nur Spritzen und Pillen bekommen. Außer Magenschmerzen hatte er nichts davon.“

Wir einigten uns schnell auf eine bildgebende Diagnostik und das Einschalten eines versierten Orthopäden. Als sich die Tür hinter meinem Patien- ten schloss, blieb ich nachdenklich zurück. Es muss doch möglich sein, dass sich Patienten lieber uns Hausärzten als Heilpraktikern anvertrauen!

Wahrscheinlich müssten wir aber dafür an unserer Patientenkommunikation arbeiten. Eine große Aufgabe! Anfangen könnte man vielleicht mit einer provokanten Frage, um die Patienten auf den richtigen Weg zu bringen: „Möchten Sie, dass Ihr Flugzeug von einem Piloten oder einem ,Flugpraktiker' gesteuert wird?"

Dr. Frauke Höllering, Arnsberg

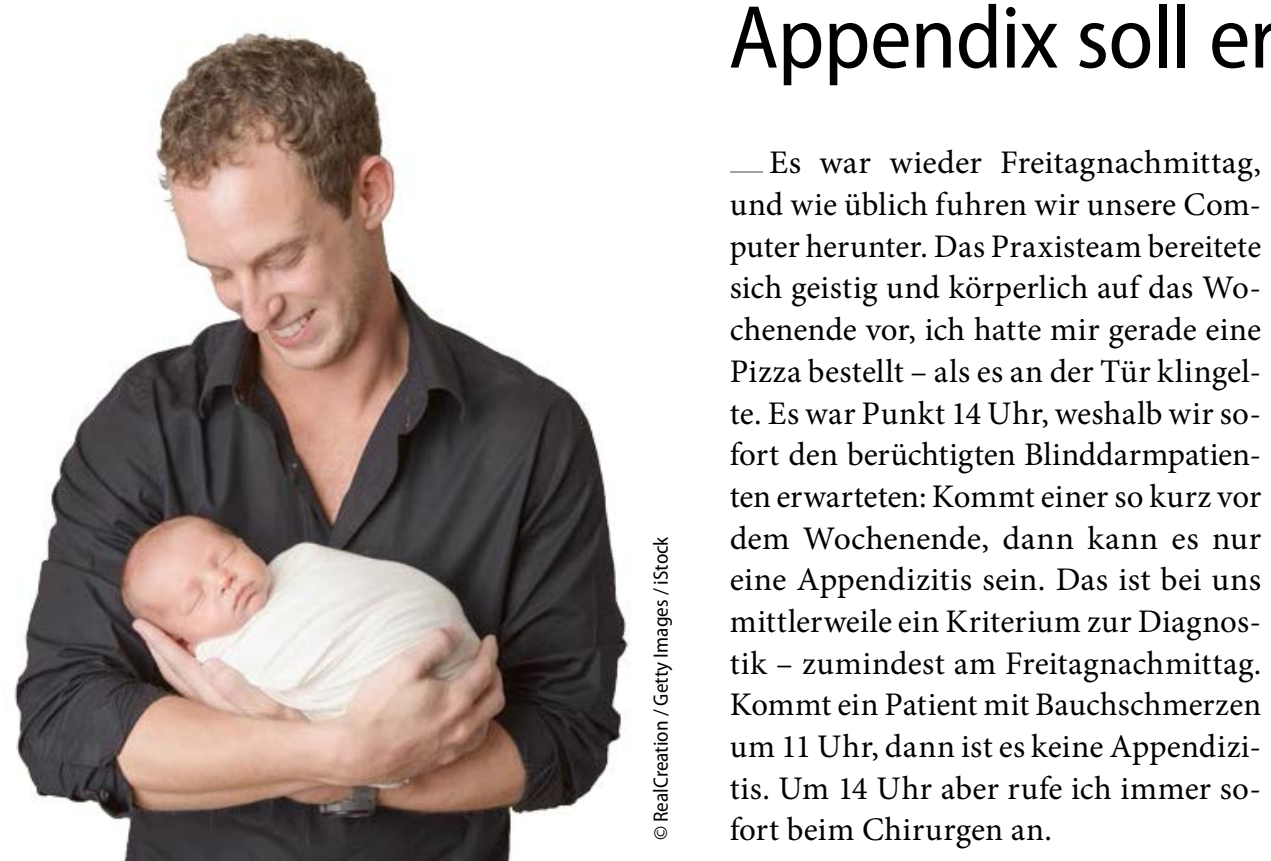

\section{Appendix soll er heißen}

Mit den Gedanken bereits bei der Anamnese öffnete ich die Tür. Wider Erwarten stand auf der anderen Seite aber kein schmerzgeplagter Patient, sondern mein Nachbar. Er wollte mir nur mitteilen, dass er Vater geworden war. „Ich habe einen Sohn!“, berichtete er mir mit Tränen in den Augen.

„Herzlichen Glückwunsch!“, antwortete ich - und fügte fröhlich hinzu: „Und falls Sie noch keinen Namen für ihn haben, dann nennen Sie ihn doch Appendix!“ Der verständnislose Blick des jungen Vaters verriet mir, was er gerade dachte: „Die spinnen, die Ärzte!“

Dr. Luise Hess, Darmstadt 